\title{
PENERAPAN SOCIAL NETWORK ANALYSIS DALAM MENGANALISIS KERJASAMA TOKOPEDIA DENGAN BOYBAND KOREA BTS
}

\author{
Ignatius Adrian Mastan ${ }^{1 *}$, Christianto ${ }^{2}$ \\ ${ }^{1,2}$ Program Studi Sistem Informasi, Fakultas Teknologi dan Desain \\ Universitas Bunda Mulia \\ Jl. Lodan Raya No. 2 Ancol, Jakarta Utara 14430 \\ *Corresponding Author: imastan@bundamulia.ac.id
}

\begin{abstract}
Tokopedia is an Indonesian technology company with a mission to achieve digital economic equity. Since its founding in 2009, Tokopedia has transformed into an influential unicorn not only in Indonesia but also in Southeast Asia. On October 7, 2019, Tokopedia announced a South Korean music group, BTS, to become the new brand ambassador for Tokopedia. BTS is a global mega star group from South Korea which is shaded by Big Hit Entertainment. Consisting of seven members including RM, Jin, SUGA, j-hope, Jimin, V, and Jung Kook, BTS was founded in 2013 and has had worldwide success. The extraordinary growth and achievements achieved by BTS have managed to break records in recent years so that BTS is designated as the persona of the Tokopedia brand. Through this collaboration, the public and BTS fans are expected to be closer to their inspirational figure. The various types of marketing currently carried out by Tokopedia in collaboration and collaboration with BTS have had a lot of impact on Tokopedia's sales. One of the marketing efforts that has been done by Tokopedia is using Twitter. Twitter is one of the social media used to attract consumers to buy products sold on Tokopedia. Using Social Network Analysis (SNA) provides a statistical tool for examining relational data not only on the characteristic attributes of individual actors, and focuses on explaining the patterns of relationships between actors, and analyzing the structure of these patterns. Social etwork representation is expressed in graph form because graph is the most fundamental type of social network representation. Social Network Analysis (SNA) argues that the relationship between nodes is important. The focus of Social Network Analysis (SNA) is on knowing the actors/nodes involved and how relationships occur. This study uses Social Network Analysis (SNA) to produce a structure of relationship data patterns between the collaboration between Tokopedia and Korean Boyband BTS which can help Tokopedia to review the collaboration that has been done. Tokopedia can take action in collaborating with BTS, to continuing or stopping or replacing with new brand ambassadors.
\end{abstract}

Keywords: social network analysis, tokopedia, twitter, marketing, brand ambassador. 


\begin{abstract}
ABSTRAK
Tokopedia merupakan perusahaan teknologi Indonesia dengan misi mencapai pemerataan ekonomi secara digital. Sejak didirikan pada tahun 2009, Tokopedia telah bertransformasi menjadi sebuah unicorn yang berpengaruh tidak hanya di Indonesia tetapi juga di Asia Tenggara. Pada 7 Oktober 2019, Tokopedia mengumumkan grup musik asal Korea Selatan, BTS menjadi brand ambassador baru untuk Tokopedia. BTS adalah grup mega bintang global asal Korea Selatan yang dinaungi oleh Big Hit Entertainment. Terdiri dari tujuh anggota termasuk RM, Jin, SUGA, j-hope, Jimin, V, dan Jung Kook, BTS didirikan pada tahun 2013 dan telah sukses mendunia. Pertumbuhan serta pencapaian luar biasa yang diraih oleh BTS berhasil memecahkan rekor dalam beberapa tahun terakhir sehingga BTS ditetapkan sebagai persona brand Tokopedia. Melalui kolaborasi ini, masyarakat serta penggemar BTS diharapkan bisa semakin dekat dengan sosok inspiratif mereka. Berbagai macam pemasaran saat ini yang telah dilakukan oleh Tokopedia dengan kolaborasi dan kerja sama dengan BTS telah banyak membawa dampak bagi penjualan Tokopedia. Salah satu pemasaran yang telah dilakukan oleh Tokopedia adalah dengan menggunakan twitter. Twitter merupakan salah satu sosial media yang digunakan untuk menarik minat konsumen untuk membeli produk yang dijual di Tokopedia. Dengan menggunakan Social Network Analysis (SNA) memberikan alat statistik untuk memeriksa data relasional bukan hanya pada karakteristik atribut aktor individu, dan berfokus pada menjelaskan pola hubungan antara aktor, dan menganalisis struktur pola-pola ini. Representasi social network dinyatakan dalam bentuk graf dikarenakan graf merupakan tipe representasi social network yang paling fundamental. Social Network Analysis (SNA) berpendapat bahwa hubungan antar nodes sesuatu yang penting. Fokus SNA untuk mengetahui actors/nodes yang terlibat dan bagaimana hubungan terjadi. Penelitian ini menggunakan Social Network Analysis (SNA) untuk menghasilkan struktur pola data relasi antara kerjasama Tokopedia dan Boyband Korea BTS yang dapat membantu pihak Tokopedia dalam me-review kembali kerjasama yang telah dilakukan. Dengan demikian Tokopedia dapat mengambil tindakan dalam melakukan kerja sama dengan BTS yaitu melanjutkan atau menghentikan dan mengganti dengan brand ambassador yang baru.
\end{abstract}

Kata kunci: social network analysis, tokopedia, twitter, marketing, brand ambassador.

\title{
PENDAHULUAN
}

Perkembangan teknologi khususnya media sosial mengubah gaya informasi dan teknologi ke arah yang jauh lebih berkembang terutama dalam mendapatkan data mengenai perilaku manusia terhadap apa yang mereka sukai dan apa yang mereka biasa kerjakan. Pengguna media sosial yang semakin meningkat setiap tahunnya menjadikan media sosial menjadi tools perusahaan untuk melihat konsumennya dalam mempelajari perilaku manusia saat ini. Dikarenakan 
masyarakat Indonesia yang sangat adaptif terhadap teknologi menyebabkan peningkatan pengguna media sosial di Indonesia. Dikutip dari website We Are Social (2017), pada tahun 2017, terjadi peningkatan dari 79 juta pengguna pada Januari 2016 menjadi 106 juta pengguna pada Januari 2017. Menurut Mangold (2009) perusahaan harus mengetahui analisis media sosial dengan cara yang tepat sesuai dengan rencana bisnis mereka.

Perkembangan media sosial di Indonesia disebabkan karena adanya perkembangan internet di Indonesia. Berdasarkan riset dari We Are Social (2017) tanggal 26 Januari 2017 terjadi peningkatan pengguna internet di Indonesia selama setahun, mulai Januari 2016 sampai Januari 2017, yakni sebanyak 132,7 juta pengguna pada Januari 2017 dari 88,1 juta pengguna pada Januari 2016. Perkembangan internet menyebabkan pula perubahan bisnis konvensional menjadi bisnis yang berbasis digital sehingga muncul e-commerce. Dari survei yang dilakukan badan survei telematika, We Are Social bahwa terjadi peningkatan sebesar $12 \%$ menjadi 24,74 juta pengguna internet yang berbelanja secara online melalui e-commerce. Berbagai jenis e-commerce terdapat di Indonesia, salah satunya adalah bisnis e-commerce $\mathrm{C} 2 \mathrm{C}$ (Consumer to Consumer). Data yang terkumpul dalam online dan bersifat kompleks tersebut dapat dikatakan sebagai big data. Dalam big data terdapat kemampuan untuk melihat pola yang akurat dan tersebar yang dapat dipergunakan menjelaskan pemanfaatan social computing untuk menganalisis pola yang terdapat pada big data. Social computing merupakan ilmu yang berfokus tentang perilaku sosial dan konteks sosial menggunakan sistem komputasi (Alamsyah, 2013). Salah satu tool dari social computing yaitu Social Network Analysis (SNA) yang merupakan teknik penelitian berfokus pada identifikasi dan membandingkan hubungan jaringan antara kata, kalimat, interaksi, dan sistem untuk model interaksi yang menghasilkan pengetahuan atau informasi yang baru (Hunter, 2014).

Dalam penelitian ini Social Network Analysis akan menunjukkan bagaimana customer memberikan feedback yang ada di dalam social media. Dalam bisnis diinginkan terciptanya sebuah persepsi konsumen yang baik. Persepsi konsumen adalah proses di mana seseorang mengorganisir dan mengartikan kesan dari panca indera dalam tujuan untuk memberi arti dalam lingkungan mereka. Dapat dilihat aspek yang harus dibenahi oleh perusahaan untuk membenahi persepsi konsumen. Masalah yang akan dianalisis adalah pengembangan social computing dalam menganalisis big data. Apakah perusahaan dapat memanfaatkan informasi tersebut sehingga mengetahui persepsi konsumennya melalui informasi di media sosial. Pada penelitian ini akan dilihat persepsi konsumen terhadap bisnis e-commerce yaitu Tokopedia dengan menggunakan media sosial yaitu Twitter.

\section{TINJAUAN PUSTAKA}

\section{Big Data}

Big data adalah kemampuan untuk mengelola banyak data yang berbeda, dengan kecepatan yang tepat, dan dalam kerangka waktu yang tepat untuk memungkinkan analisis real-time dan membuat data menjadi informasi sebagai dasar untuk tindakan selanjutnya (Hurwitz, 2013). Big data adalah data yang melebihi kapasitas pengolahan sistem database konvensional, data yang terlalu 
besar, perpindahan data yang terlalu cepat, atau tidak sesuai dengan struktur database. Big data memiliki tiga karakterisitk utama atau biasa disebut dengan $3 \mathrm{~V}$ yaitu Volume atau ukuran yang sangat besar, Velocity yaitu bergerak dengan cepat, dan Variety yaitu memiliki keberagaman data atau variasi dalam informasi, sehingga tidak sesuai dengan arsitektur database konvensional (Provost, 2013).

\section{User Generated Content}

User Generated Content (UGC) adalah konten yang dihasilkan dari user (Dumbill, 2012). User Generated Content adalah segala bentuk konten atau isi dalam sebuah media di dunia teknologi yang ada pada saat ini seperti blog, wiki, forum diskusi, chatting, tweet, podcasting, pin, gambar digital, video, file hingga berbagai bentuk konten media lainya yang terbentuk melalui buatan dari para pengguna sistem atau layanan online. Dikarenakan User Generated Content telah berkembang, sehingga partisipasi konsumen menjadi hal yang penting sebagai marketing inteligence untuk perusahaan dengan mengolah menggunakan metode dan teknik yang tepat terhadap User Generated Content (Moens, 2014).

\section{Social Computing}

Social computing adalah sebuah ilmu yang mempelajari mengenai perilaku sosial dan konteks sosial menggunakan computational system (Liu, 2009). Social computing merupakan salah satu metode pengolahan data User Generated Content. Social computing juga merujuk kepada aplikasi digital yang dapat memudahkan interaksi dan kolaborasi di mana pengguna juga dapat berpartisipasi menjadi pembuat konten, bukan hanya sebagai pengguna akhir. Dengan adanya aplikasi semacam ini, para pengguna seperti pelanggan, pelajar, penduduk, atau para pegawai dari sebuah perusahaan memiliki peranan penting pembentukan citra suatu produk atau jasa

\section{Social Network Analysis}

Perkembangan social network saat ini semakin berkembang pesat. Dalam suatu komunitas social network, komunitas merupakan wadah yang nyaman untuk saling bertukar informasi antar anggota grup. Hal ini membuat sebuah grup pada media sosial menjadi ladang informasi, baik informasi yang disebutkan secara eksplisit ataupun secara implisit. Pemetaan dan pengukuran alur interaksi dilengkapi dengan analisis pola alur interaksi, yang didefinisikan sebagai Social Network Analysis (SNA). Social Network Analysis memandang hubungan sosial dalam hal teori jaringan yang terdiri dari node dan hubungan (juga disebut tepi, link, atau koneksi). Node adalah aktor individual dalam jaringan, dan hubungan adalah hubungan antara aktor. Struktur berbasis grafik yang dihasilkan seringkali sangat kompleks. Terdapat banyak jenis hubungan antara node.

Penelitian di sejumlah bidang akademik telah menunjukkan bahwa jaringan sosial beroperasi pada banyak tingkatan, dari keluarga sampai ke tingkat negara, dan memainkan peran penting dalam menentukan cara sebuah masalah diselesaikan, organisasi dijalankan, dan sejauh mana individu berhasil dalam mencapai tujuannya. Social Network Analysis memberikan alat statistik untuk memeriksa data relasional bukan hanya pada karakteristik atribut aktor individu, dan berfokus pada 
menjelaskan pola hubungan antara aktor, dan menganalisis struktur pola-pola ini. Representasi social network dinyatakan dalam bentuk graf dikarenakan graf merupakan tipe representasi social network yang paling fundamental. Social Network Analysis berpendapat bahwa hubungan antar nodes sesuatu yang penting. Fokus Social Network Analysis untuk mengetahui actors/nodes yang terlibat dan bagaimana hubungan terjadi. Dengan siapa aktor terhubung, seberapa kuat hubungan terjadi, seperti apa hubungan terjadi, apakah hubungan terjadi satu arah atau dua arah, bagamana hubungan difasilitasi, melalui media apa hubungan terjadi hingga ke aplikasi lainnya seperti siapa yang memiliki hubungan (ties) paling banyak, siapa yang terisolasi dalam network, bagaimana jarak (gap) dan rentang (length) antar masing-masing nodes, di mana terjadi bottleneck, siapa yang menjadi key player dan sebagainya. Tiga jenis sentralitas individu paling populer adalah sebagai berikut:

a. Degree centrality: jumlah koneksi yang dimiliki sebuah node.

b. Closseness centrality: jarak rata-rata antara node dengan semua node yang lain di jaringan. Ukuran ini menggambarkan kedekatan node ini dengan node lain. Semakin dekat, semakin terhubung orang tersebut dengan lainnya.

c. Betweeness centrality: ukuran ini memperlihatkan peran sebuah node menjadi bottleneck. Semakin banyak jalan yang harus melewati persimpangan itu (misal tidak ada jalan alternatif), maka semakin penting arti persimpangan tersebut.

\section{METODE PENELITIAN}

Dalam penelitian akan digunakan prosedur penelitian dengan langkahlangkah seperti terlihat pada Gambar 1.

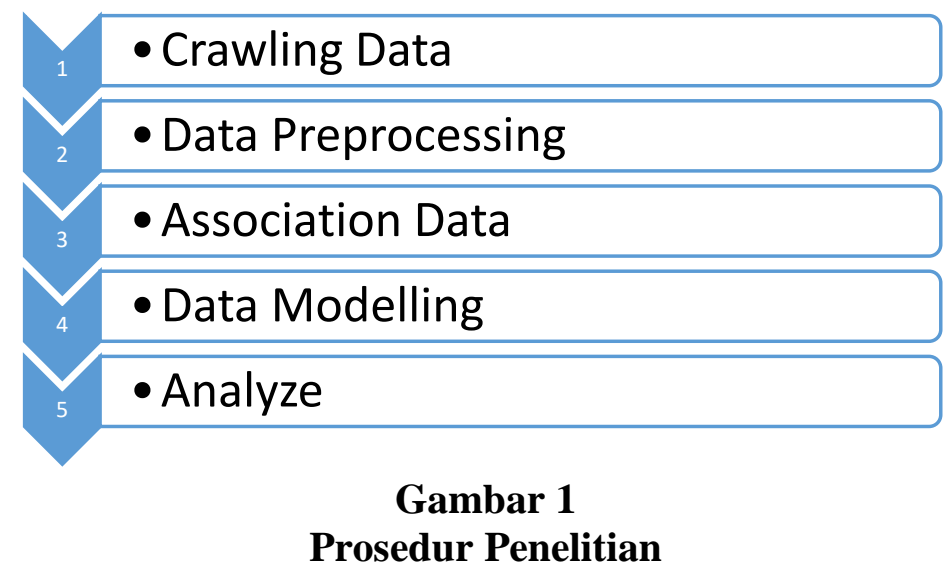

Prosedur Penelitian dapat dijabarkan sebagai berikut:

1. Tahap pertama adalah crawling data menggunakan metode Social Network Analysis pada website Netlytics.org dengan mengekstrak informasi pada komentar, reply, tweet, mention pada konsumen di media sosial Twitter. Informasi diperoleh melalui crawling data di media sosial Twitter. Penggalian informasi dilakukan di media sosial Twitter karena bersifat terbuka sehingga mempermudah crawling data dan banyak orang di Indonesia menggunakan Twitter. Crawling data di media sosial mengenai informasi, opini, pengalaman 
konsumen terkait bisnis e-commerce Tokopedia dan Boyband Korea BTS. Komentar yang melambangkan persepsi dari konsumen di media sosial tersebut selanjutnya akan diproses pada tahap data preprocessing untuk membagi setiap kata dalam sebuah komentar.

2. Tahap kedua adalah data preprocessing melalui 3 tahap lagi, yaitu: tokenization, filtering stopwords, dan stemming. Pada tahap tokenization dilakukan proses pemecahan kalimat/relasi menjadi kata-kata dan hubungan sehingga memudahkan analisis asosiasi jaringan. Langkah selanjutnya adalah filtering stopwords yang digunakan untuk membersihkan data dari frasa atau kata-kata yang tidak berguna. Tahap akhir dari preprocessing data adalah stemming yaitu proses pembersihan imbuhan yaitu prefiks, sufiks, infiks, dan konfiks untuk menggabungkan kata yang berasal dari kata dasar dan interaksi yang sama untuk analisis asosiasi tahap berikutnya. Kata yang sudah disaring dan melewati tahap preprocessing data menjadi kumpulan kata-kata besar melalui word cloud generator serta inisialisasi jaringan. Dengan demikian, data kualitatif diperoleh pada layanan e-commerce melalui preprocessing data agar menjadi data yang berkualitas baik sebelum masuk ke dalam proses asosiasi. Hasil dari word cloud generator adalah kata dominan yang melambangkan persepsi dominan konsumen yang akan dilakukan pengolahan asosiasi kata tidak hanya memetakan kata, namun juga memetakan jaringan dari setiap hubungan sehingga terjadinya interaksi antar user dengan objek penelitian.

3. Pada tahap ketiga, data dan jaringan diasosiasi. Tiap kata akan dihubungkan dengan kata lain dan jaringan lain yang muncul dalam satu komentar. Kemudian tahap pemodelan dengan menggunakan aplikasi yaitu Gephi dan analisis dengan modularitas untuk melihat asosiasi kata yang terbentuk.

4. Pada tahap keempat, dilakukan pemodelan data pada asosiasi persepsi konsumen dibutuhkan untuk melihat bagaimana persepsi bisnis e-commerce melalui jaringan yang ada sehingga perusahaan dapat menjawab bagaimana layanan mereka di benak konsumen. Pada jaringan interaksi akan didapat hasil akhir berupa hubungan setiap interaksi yang membentuk kluster melalui customer feedback konsumen pada media sosial dan menunjukkan asosiasi persepsi konsumen terhadap layanan yang diberikan oleh e-commerce. Asosiasi persepsi konsumen merupakan kumpulan komentar yang disampaikan oleh konsumen di media sosial yang berkaitan dengan persepsi mereka.

5. Tahap kelima adalah analyze pada setiap interaksi yang dibangun konsumen memiliki karakteristik masing-masing yang dapat dibagi menjadi beberapa kelompok berdasarkan kesamaan. Hasil dari asosiasi persepsi konsumen adalah ringkasan dari komentar, dan jaringan konsumen terkait yang dapat digunakan sebagai strategi perusahaan untuk meningkatkan retensi pelanggan dan brand image.

\section{HASIL PENELITIAN DAN PEMBAHASAN \\ Teknik Pemodelan}

Teknik pemodelan dengan menggunakan aplikasi yaitu Gephi dan analisis dengan modularitas untuk melihat asosiasi kata yang terbentuk. Memodelkan data pada asosiasi persepsi konsumen dibutuhkan untuk melihat bagaimana persepsi 
bisnis $e$-commerce melalui jaringan yang ada sehingga perusahaan dapat menjawab bagaimana layanan mereka di benak konsumen. Pada jaringan interaksi didapat hasil akhir berupa hubungan setiap interaksi yang membentuk kluster melalui customer feedback konsumen pada media sosial dan menunjukkan asosiasi persepsi konsumen terhadap layanan yang diberikan oleh e-commerce. Asosiasi persepsi konsumen merupakan kumpulan komentar yang disampaikan oleh konsumen di media sosial yang berkaitan dengan persepsi mereka.

\section{Crawling Data}

Crawling data dilakukan dengan mengambil sampel terbanyak dari setiap interaksi yang diperoleh oleh website Netlytic.org.

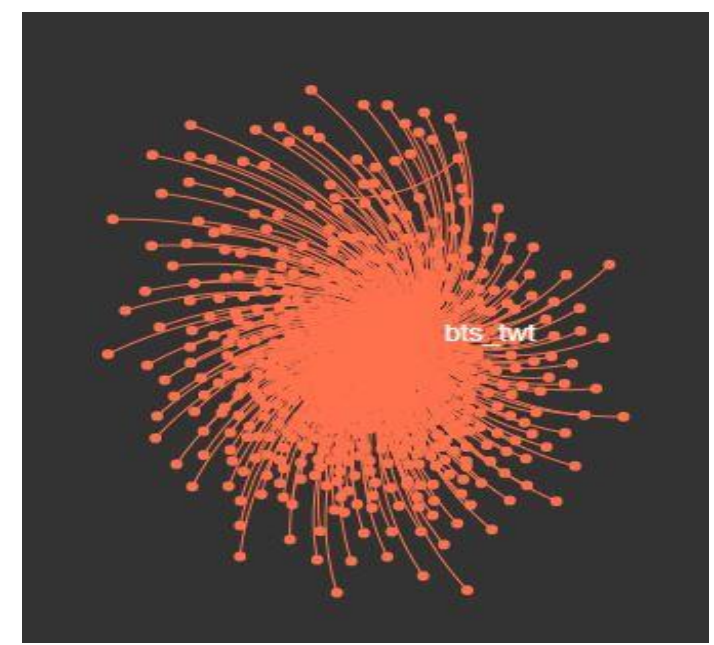

Gambar 2

Relasi BTS dengan Followers-nya

Gambar 2 adalah gambar yang mendeskripsikan BTS dengan total degree mencapai 736.

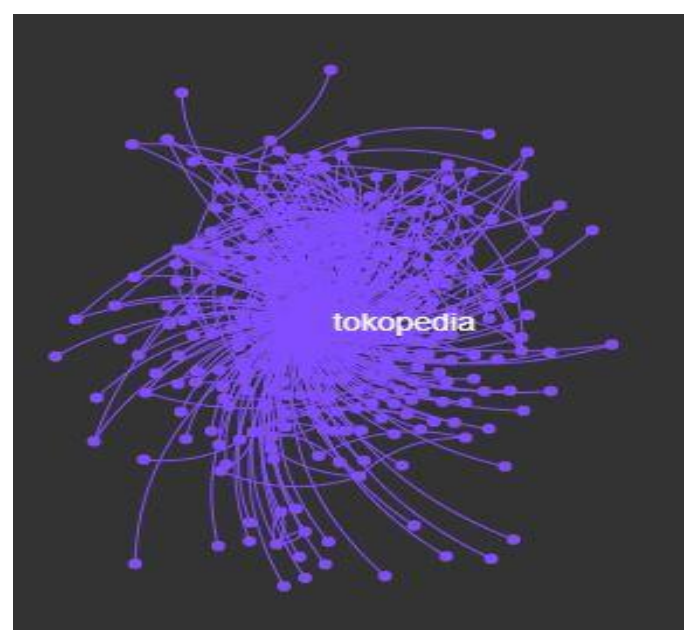

Gambar 3

Relasi Tokopedia dengan Followers-nya 
Gambar 3 adalah gambar yang mendeskirpsikan Tokopedia dengan total degree mencapai 510.

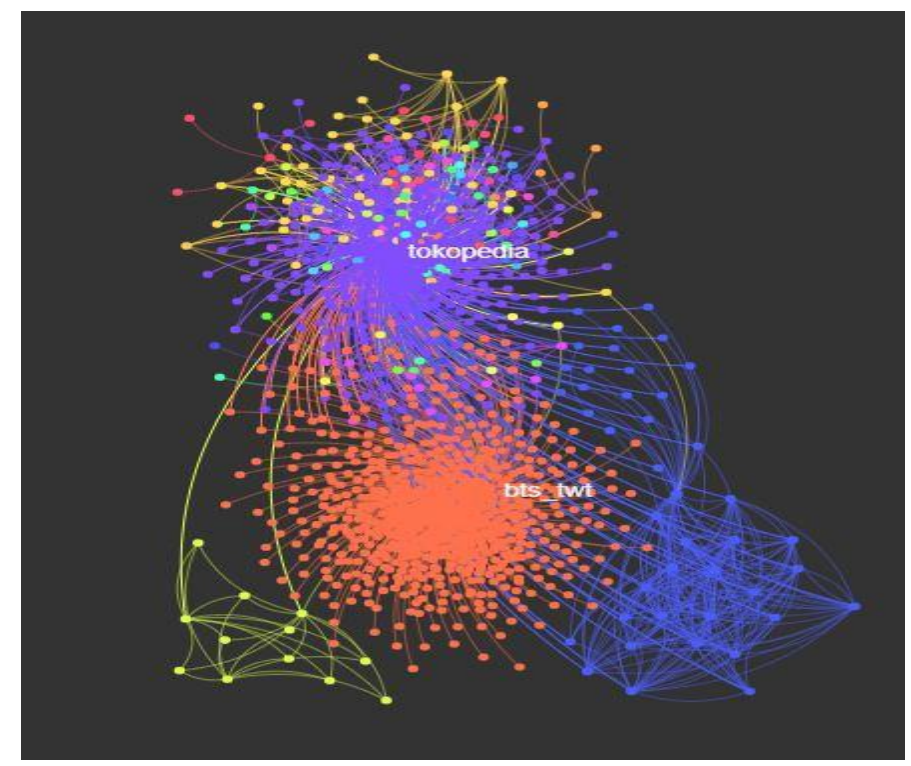

Gambar 4

Semua Interaksi yang Terjadi antara Twitter Tokopedia dengan BTS

Network Properties:

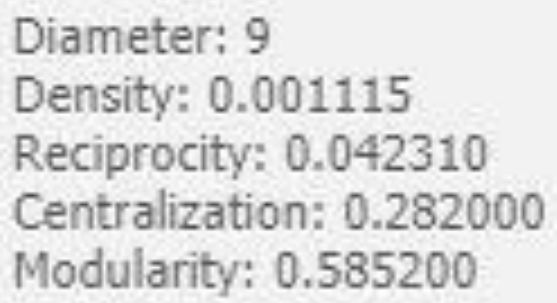

Gambar 5

Network Properties yang terjadi antara Tokopedia dan BTS

\section{Network Properties}

Diameter

Diameter menghitung langkah terpendek antara jarak terpanjang antara dua peserta jaringan. Langkah ini menunjukkan ukuran jaringan, dengan menghitung jumlah node yang dibutuhkan untuk mendapatkan dari satu sisi ke sisi lain. Netlytic memperoleh hasil diameter yaitu 9. Dengan demikian, Netlytic telah memberitahukan bahwasanya jarak satu node untuk menuju node lainnya yang terpendek langkahnya maksimal 9 edges. 


\section{Density}

Density (kepadatan) adalah proporsi ikatan yang ada untuk jumlah total ikatan mungkin dalam jaringan. Dengan kata lain, itu dihitung dengan membagi jumlah ikatan yang ada (koneksi) dengan jumlah ikatan yang mungkin. Langkah ini membantu untuk menggambarkan seberapa dekat peserta dalam jaringan. Density pada Network Twitter Tokopedia bernilai 0,001115 yang berarti bahwa keadaan jaringan tidak padat. Pada jaringan ini, orang-orang yang terlibat kurang dekat dan arus informasi berlangsung lambat. Peserta jejaring sosial ini kurang banyak berinteraksi dan berbicara dengan peserta lainnya.

\section{Resiprocity}

Reciprocity (timbal balik) adalah proporsi ikatan yang menunjukkan komunikasi dua arah (juga disebut ikatan timbal balik) dalam kaitannya dengan jumlah total ikatan yang ada. Hal ini diukur dengan jumlah ikatan timbal balik dalam kaitannya dengan jumlah total ikatan dalam jaringan (tidak semua ikatan mungkin). Sebuah nilai yang lebih tinggi menunjukkan banyak peserta memiliki dua percakapan, sedangkan nilai timbal balik yang rendah menunjukkan banyak percakapan adalah satu-sisi, sehingga ada sedikit kembali dan sebagainya percakapan. Reciprocity pada jejaring Twitter Tokopedia bernilai 0,042310 yang berarti tingkat timbal balik rendah. Hal tersebut dikarenakan Tokopedia dan BTS sebagai node yang berpengaruh sangat jarang membalas Tweet yang ditujukan kepadanya bahkan hampir tidak pernah. Nilai yang hanya kecil tersebut diperoleh melalui para followers yang saling membalas Tweet followers lainnya.

\section{Centralization}

Sentralisasi mengukur tingkat sentralitas rata-rata semua nodes dalam sebuah jaringan. Ketika jaringan memiliki nilai sentralisasi tinggi lebih dekat ke-1, itu menunjukkan ada peserta sentral beberapa yang mendominasi arus informasi dalam jaringan. Jaringan dengan pengukuran rendah sentralisasi lebih dekat ke-0 dianggap didesentralisasikan di mana informasi mengalir lebih bebas antara banyak peserta centralization pada Network Twitter Tokopedia bernilai 0,282000. Nilai tersebut tergolong rendah karena lebih mendekati angka 0 . Hal tersebut mengindikasikan bahwa didalam Network Twitter Tokopedia tak hanya terdiri dari 1 peserta yang berada di tengah dan mendominasi arus informasi. Apabila kita melihat ke visualisasi Network Twitter Tokopedia, kita dapat melihat bahwa ada 2 tokoh sentral yaitu "BTS" dan "Tokopedia". Selain itu juga terdapat banyak nodes di antara kedua tokoh sentral yang memiliki klusternya masing-masing. Hal tersebut mengakibatkan informasi cenderung terdesentralisasi atau informasi mengalir lebih bebas di antara nodes.

\section{Modularity}

Modularitas menentukan apakah kluster ditemukan mewakili masyarakat yang berbeda dalam jaringan. Nilai-nilai yang lebih tinggi menunjukkan perbedaan yang jelas antara masyarakat yang diwakili oleh kluster di Netlytic. Nilai-nilai rendah modularitas, biasanya kurang dari 0,5, menunjukkan bahwa kluster, ditemukan oleh Netlytic, akan tumpang tindih lebih; jaringan lebih cenderung terdiri 
dari suatu kelompok yang mendominasi. Modularity pada Network Twitter Tokopedia bernilai 0,585200. Nilai tersebut digolongkan dalam nilai modularitas yang tinggi karena telah melebihi angka 0,5 lebih sedikit. Hal tersebut mengindikasikan bahwa dalam kluster, pesertanya berasal dari perwakilan berbagai kalangan yang berbeda-beda. Hal tersebut merupakan hal yang baik karena peserta terdistribusi merata.

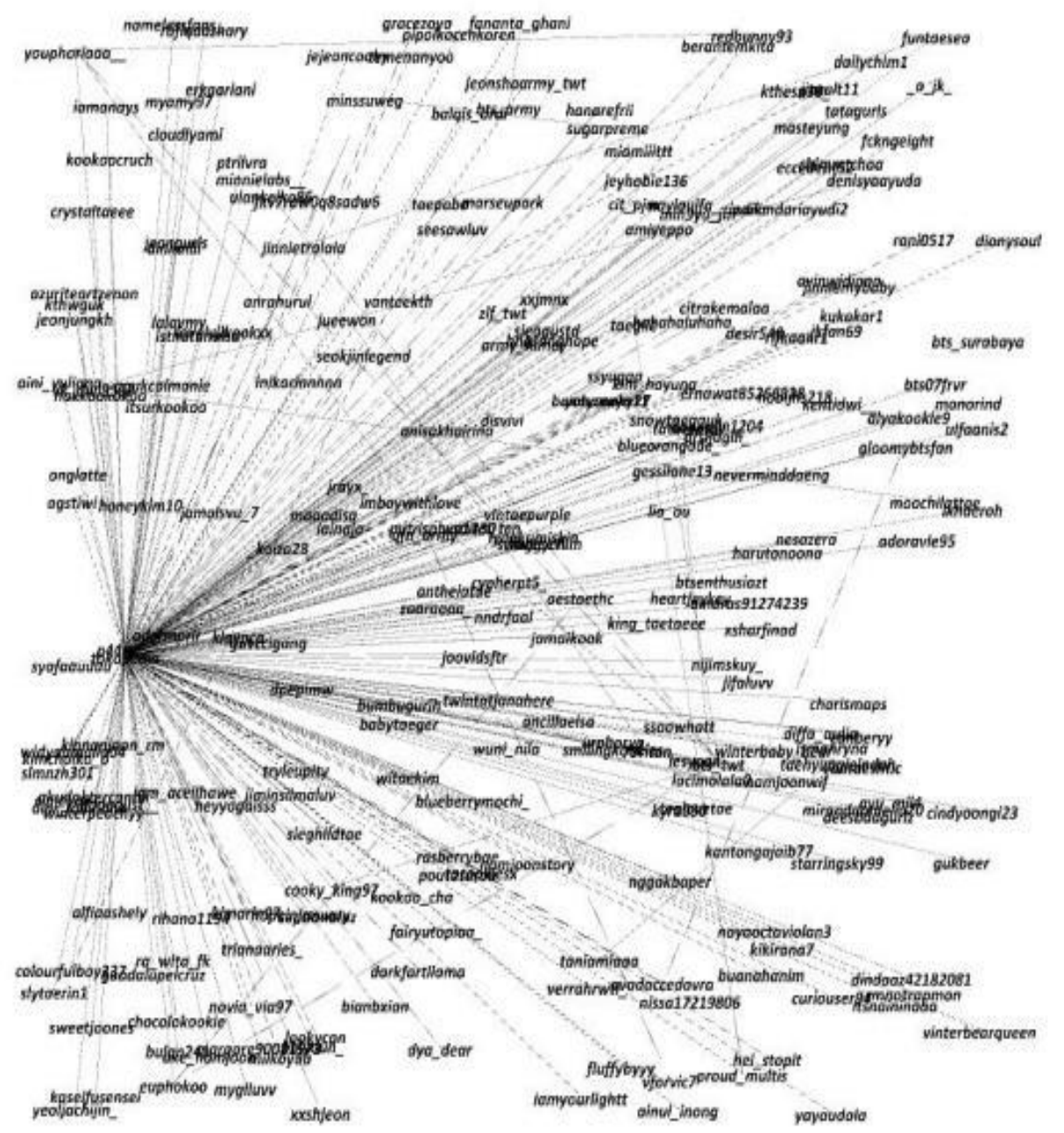

Gambar 6

Analisa Jaringan dengan Aplikasi Gephi

\section{SIMPULAN}

Di dalam melakukan interaksinya Tokopedia banyak dibantu oleh Twitter BTS dalam melakukan trend topic sebagai media promosi marketing. Hal ini menunjukkan bahwa relasi yang ditujukan user dalam melakukan mention Tokopedia menjadi hot topics karena mencapai lebih dari 0,5 di dalam angka modularnya. Kedua belah pihak mendapatkan keuntungan dengan sama-sama saling membantu dalam meraih follower, dan sama-sama melakukan trend untuk menjaga tingkat relasi antar user. Dengan demikian terdapat hubungan yang 
signifikan antara BTS sebagai brand ambassador dari Tokopedia, sehingga dengan demikian sebaiknya Tokopedia tetap menggunakan BTS sebagai brand ambassador dalam kegiatan marketing agar semakin meningkatkan volume penjualan.

\section{SARAN}

Saran yang dapat diberikan oleh peneliti adalah agar Tokopedia selalu melakukan evaluasi terhadap brand ambassador-nya secara berkala dalam kegiatan marketing-nya dan aktif dalam melakukan pendekatan dengan user melalui media sosial selain Twitter, yaitu Instagram, Facebook, dan media sosial lainnya, sehingga dapat semakin merajai pasar e-commerce di Indonesia.

\section{DAFTAR PUSTAKA}

Alamsyah. 2013. The Role of Social Network Analysis for Knowledge Management. Jurnal Manajemen Indonesia, Vol. 12, No. 4, pp. 309-314.

Dumbill. 2012. Big Data Now: 2012 Edition. “What Is Big Data?. USA: O’Reilly Media, Inc.

Hunter. 2014. A Novel Method of Network Social Analysis. Open Journal of Modern Linguistics, Vol. 4, pp. 350-366.

Hurwitz. 2013. Big Data For Dummies. Hoboken. NJ: John Wiley \& Sons, Inc.

Liu. 2009. Social Computing and Behavioral Modeling. USA: Phoenix Arizona.

Mangold. 2009. Social Media: The New Hybrid Element of The Promotion Mix. US: Business Horizons.

Moens. 2014. Mining User Generated Content. Boca Raton: CRC Press.

Provost. 2013. Data Science for Business. 1005 Gravenstein Highway North, Sebastopol: O'Reilly Media, Inc.

We Are Social. 2017. diakses dari https://wearesocial.com/special-reports/digitalsoutheast-asia- 2017/ pada tanggal 25 Oktober 2017. 